\title{
Postural alignment in children with Duchenne muscular dystrophy and its relationship with balance
}

\author{
Cyntia R. J. A. Baptista ${ }^{1}$, Andreia A. Costa ${ }^{2}$, Tatiana M. Pizzato ${ }^{1,3}$, \\ Francine B. Souza ${ }^{2}$, Ana C. Mattiello-Sverzut ${ }^{1}$
}

\begin{abstract}
Background: In Duchenne muscular dystrophy, functional deficits seem to arise from body misalignment, deconditioning, and obesity secondary to weakness and immobility. The question remains about the effects of postural deviations on the functional balance of these children. Objectives: To identify and quantify postural deviations in children with DMD in comparison to non-affected children (eutrophic and overweight/obese), exploring relationships between posture and function. Method: This case-control study evaluated 29 participants aged 6 to 11 years: 10 DMD (DG), 10 eutrophic (EG), and 9 overweight/obese (OG). Digital photogrammetry and SAPo program were used to measure postural alignment and the Pediatric Balance Scale (PBS) was used to measure balance. The Kruskall-Wallis and Dunn post-hoc tests were used for inter-group comparison of posture and balance. Spearman's coefficient tested the correlation between postural and balance variables. Results: The horizontal pelvic alignment data indicated that the anteversion of the DG was similar to that of the OG and twice that of the EG $(\mathrm{p}<0.05)$. Compared to the EG, the DG and OG showed an increased forward position of the center of mass $(p<0.05)$. There was a moderate and weak correlation between the PBS score and horizontal pelvic alignment (0.58 and 0.47-left/right). The PBS showed a weak correlation with asymmetries in the sagittal plane (-0.39). The PBS scores for the OG and EG suggest that obesity did not have a deleterious effect on balance. Conclusions: The balance deficit in children with DMD was accompanied by an increased forward position of the center of mass and significant pelvic anteversion that constitutes a compensatory strategy to guarantee similar performance to the children not affected by the disease.
\end{abstract}

Keywords: balance; neuromuscular diseases; posture; photogrammetry.

\section{HOW TO CITE THIS ARTICLE}

Baptista CRJA, Costa AA, Pizzato TM, Souza FB, Mattiello-Sverzut AC. Postural alignment in children with Duchenne muscular dystrophy and its relationship with balance. Braz J Phys Ther. 2014 Mar-Apr; 18(2):119-126. http://dx.doi.org/10.1590/ S1413-35552012005000152

\section{Introduction}

Postural alignment promotes the support and mobility of the segments of the body ${ }^{1}$. The accelerated somatic growth during childhood can induce the development of numerous postural defects, compromising physical development ${ }^{2}$. In neuromuscular diseases, postural deviations are the result of pathological processes of the skeletal muscle itself, often associated with changes in bones and joints and in the central nervous system ${ }^{3,4}$. A common feature of neuromuscular disease is muscle weakness and imbalance that leads to postural deviations and functional disabilities.

In the case of Duchenne muscular dystrophy (DMD), progressive muscle weakness particularly in the proximal and extensor muscles is responsible for the muscle shortening that becomes evident by the age of $13^{4}$. Toe walking is seen by the age of
8 and this has been attributed to shortening of the calcaneous tendons and iliotibial bands. As walking and other abilities deteriorate, compensatory spinal deformities such as scoliosis and hyperlordosis start developing and finally culminate in complete functional dependence 5 .

Although recent studies indicate the existence of a relationship between balance tests and motor functions ${ }^{6}$, the repercussions of postural deviations on quiet standing in children with neuromuscular diseases have been little investigated ${ }^{7}$. Barrett et al. ${ }^{7}$ studied static balance in 8 children with DMD using the force platform, comparing their performance with and without a knee-ankle-foot orthosis. The use of the orthosis increased postural stability, with the center of mass $(\mathrm{CoM})$ projecting closer to the ankle joint. Thus,

\footnotetext{
${ }^{1}$ Department of Biomechanics, Medicine and Rehabilitation of the Locomotor Apparatus, School of Medicine of Ribeirão Preto, Universidade de São Paulo (USP), Ribeirão Preto, SP, Brazil

${ }^{2}$ Physical Therapy Course, School of Medicine of Ribeirão Preto, USP, Ribeirão Preto, SP, Brazil

${ }^{3}$ Graduate Program, School of Medicine of Ribeirão Preto, USP, Ribeirão Preto, SP, Brazil

Received: 12/19/2012 Revised: 05/10/2013 Accepted: 11/18/2013
} 
improvement of postural alignment with the orthosis appeared to favor balance while standing.

It is known that, in the early stages of disease (5 to 6 years), children with DMD present with a wider anterior-posterior and medial-lateral range of motion than in the stage of gait loss ${ }^{8}$. Children with DMD have less ability to control the CoM within the base of support when compared to healthy children of comparable age ${ }^{9}$. Kelly et al. ${ }^{9}$ compared the results of stabilometry between 13 children with DMD and 57 healthy children. In contrast to healthy children, the ratios of CoM excursions tended to decrease with age in children with DMD. Ratios of reduced CoM excursions were considered a strategy to deal with balance in the presence of progressive weakness. Although the sensory processing is intact in this disease, the skeletal muscle system does not appear to be able to generate stabilizing forces to regain balance. As a consequence, excessive expansion of the base of support, hyperextension of the knees, and lumbar hyperlordosis are observed in the standing position as compensatory adaptations to muscle weakness ${ }^{10}$.

Another aspect to consider in DMD is a detrimental effect of obesity on balance. The increment in the body mass index (BMI) that affects half of DMD children is associated with reduced levels of physical activity and glucocorticoid therapy ${ }^{11}$. There is some evidence that excess weight and obesity in children without neuromuscular diseases can affect balance ${ }^{11,12}$, although this is a controversial finding ${ }^{13}$.

Since balance control during quiet standing requires only minimal muscle activity, muscle weakness alone does not explain the exacerbated balance deficit in children with DMD. Within this context, the loss of balance and most functional deficits seem to arise from body misalignment and loss of conditioning secondary to muscle weakness ${ }^{10}$. However, to our knowledge, there are no studies investigating the effect of postural deviations on balance in children with DMD. Information about the role and the extent of postural misalignment in these children would contribute to the development of procedures for the management of progressive neuromuscular diseases.

Considering that the ideal postural alignment is theoretical and the limits of the normal and abnormal postural alignment are not established, the comparison between healthy and DMD children could help to verify the impact of postural alignment on balance using a functional scale. Therefore, the objective of the present study was to identify and quantify postural deviations in children with DMD, eutrophic children, and overweight/obese children. Afterwards, the postural deviations obtained in
DMD children were compared with eutrophic and overweight/obese children to establish associations between posture and functional balance.

\section{Method}

\section{Subjects}

This case-control study was composed of a sample of 29 participants aged 6 to 11 years: 10 children with DMD (DG), 10 eutrophic control (EG), and 9 obese control (OG). With the aim to compare balance and posture between groups, all participants were submitted to one session of tests to determine Pediatric Balance Scale (PBS) scores, angles, and distances of postural alignment. Because of the relevance of BMI to the objective of this research, overweight/obese participants were incorporated. The criteria for inclusion in the DG were: a medical diagnosis of DMD, follow-up at the university's Neuromuscular Disease Outpatient Clinic, preserved capacity for unsupported standing (with or without the use of orthoses), and minimum cognitive capacity to perform the proposed tests. The criteria for inclusion in the EG were age comparable to that of the children in the EG, no history of fractures, rheumatic diseases or any other disease that triggers musculoskeletal deformities, and no history of orthopedic surgery. The criteria for inclusion in the OG were the same as the EG plus a BMI comparable to that of the children in the EG. The exclusion criteria were any cognitive, neuromuscular or musculoskeletal aspect that constrained the progression of the tests. The study was approved by the Ethics Committee of the School of Medicine of Ribeirão Preto, Universidade de São Paulo (USP), Ribeirão Preto, SP, Brazil (protocol number. 6990/2007) and the parents or legal guardians agreed to the child's participation by signing an informed consent form.

\section{Procedures}

Each participant was submitted only once to the test procedures, which were conducted by a single, trained examiner. Anthropometric measures, balance, postural alignment, and clinical data (health condition, pre-existing diseases, and use of medications or orthotic devices) were obtained from all participants. In addition, the children with DMD were submitted to clinical evaluation and assessment of motor function using the Motor Function Measure $(\mathrm{MFM})^{14}$.

The MFM is a scale specifically developed for neuromuscular diseases and consists of 32 items that comprise static and dynamic evaluations divided into 
three dimensions (D1: standing and transfer, 13 items; D2: axial and proximal motor function, 12 items; D3: distal motor function, 7 items). A score ranging from 0 to 3 is attributed, corresponding to increasing performance, i.e. the total score obtained indicates the maximum performance in the dimensions tested (96 points) and is expressed as percentage.

The participants of the DG were named according to their ages as follows: A1, A2, A3 (6 years); B1, B2, B3 (8 years); and C1, C2, C3 (9 years); D1 (10 years); and E1 (11 years) to facilitate comparisons with the eutrophic and overweight/obese groups.

\section{Evaluation of balance}

Balance was evaluated in all groups using a standard measure, the Brazilian version of the PBS ${ }^{15}$. Its original version has been shown to be sensitive to changes in balance skills of children, especially cerebral palsy, and is an efficient diagnostic and monitoring tool ${ }^{16}$. The score attributed per task ranges from 0 to 4 according to the quality and time of execution and the total score is 56 for children older than 7 years who present typical development.

In the present study, the 14 activities of the scale were shown to the participant who then performed each task without recording the results. Next, the tests were performed and scores were attributed.

\section{Evaluation of postural alignment}

Digital photogrammetry is an adequate alternative for the quantitative evaluation of postural asymmetries ${ }^{17}$, even in children ${ }^{18}$. This technique allows the computerized measurement of angles and horizontal and vertical distances for different purposes. The following measures of postural alignment were obtained from DG, EG, and OG using the SAPo program ${ }^{19}$ : hip, knee, and shoulder angle; horizontal and vertical alignment of the anterior and posterior superior iliac spines, pelvis, scapulae, knee, spine, and head; and projection of the CoM within the base of support.

The posture images were captured with a Sony 6.0MP DSC-T9 digital camera mounted on a Vanguard VT-131 tripod at a height of $90 \mathrm{~cm}$ and parallel to the floor. The center of the camera lens overlapped the midpoint of the base of support. A plumb line was hung next to the participant as a vertical reference and was visible in all of the photographs. The line was marked at $10 \mathrm{~cm}$ intervals over a distance of $50 \mathrm{~cm}$ to facilitate calibration of the images. The support base was used as the horizontal reference and its surface was confirmed with a leveling device.
The photographic images were captured in the independent standing position in the anterior, posterior, and lateral views, with the participant wearing a bathing suit. The anatomical landmarks were identified with Styrofoam cylinders (lumbar region) and spheres (other regions) measuring $1 \mathrm{~cm}$ in diameter, which received colored adhesives (Pimaco) to increase the precision of photographic analysis by the software. Before each image acquisition, the participants were asked to walk for 10 s over an ethylene-vinyl acetate carpet to assume a posture as natural and relaxed as possible. A plantigrade impression marked on the carpet was also obtained to guarantee the same base of support in all of the photographs.

\section{Statistical analysis}

Descriptive statistics were used for exploratory data analysis. The nonparametric Kruskall-Wallis test (implemented in the R2.14 software) ${ }^{20}$ followed by Dunn's post-hoc test were used to compare postural alignment and balance score data between the DG, EG, and OG.

Spearman's correlation coefficient (rho) was used to evaluate the association between two quantitative variables (distances and angles related to posture alignment, lower limb function, and balance) for all participants. Correlations (positive or negative rho values) were defined as follows: $>0.90$, very strong; 0.70 to 0.89 , strong; 0.50 to 0.69 , moderate; 0.30 to 0.49 , weak; $<0.30$, little or no correlation.

\section{Results}

The anthropometric variables obtained by the EG, OG, and DG are shown in Table 1. The differences between groups are marked with $*$ and $\ddagger$, and the p-values are shown in the last column.

\section{Clinical and functional data}

The clinical features of each participant of the DG are shown in Table 2. Note that the lowest individual MFM scores were observed for the D1 dimension (standing position and transfer), with seven DMD children presenting values below 50\%. Based on BMI values for children ${ }^{21}$, all of the participants with DMD are classified as overweight (A2, A3, B1, $\mathrm{C} 1$, and $\mathrm{E} 1$ ) or obese (A1, C2, C3, and D1) with the exception of one eutrophic participant (B2). The DG participants had in common the use of prednisone or deflazacort and some kind of orthosis to manage ankle deformities. 
Table 1. Age and anthropometric characteristics of the participants considering eutrophic, overweight/obese and children with Duchenne muscular dystrophy. Differences between groups are shown on the last column (Kruskal-Wallis test and Dunn's post hoc test, $\mathrm{p}<0.05$ ).

\begin{tabular}{|c|c|c|c|c|c|c|c|c|c|c|}
\hline \multirow[b]{2}{*}{ Variable } & \multicolumn{3}{|c|}{$\begin{array}{l}\text { Eutrophic } \\
\text { (EG) } n=10\end{array}$} & \multicolumn{3}{|c|}{$\begin{array}{l}\text { Overweight /Obese } \\
(\text { (OG) } n=9\end{array}$} & \multicolumn{3}{|c|}{$\begin{array}{l}\text { Duchenne } \\
\text { (DG) } n=10\end{array}$} & \multirow[b]{2}{*}{$\mathrm{p}$-value } \\
\hline & $\begin{array}{l}\text { Mean } \\
(\mathrm{SD})\end{array}$ & Median & $\begin{array}{l}\text { Minimum } \\
\text { Maximum }\end{array}$ & $\begin{array}{c}\text { Mean } \\
(\mathrm{SD})\end{array}$ & Median & $\begin{array}{l}\text { Minimum } \\
\text { Maximum }\end{array}$ & $\begin{array}{c}\text { Mean } \\
(\mathrm{SD})\end{array}$ & Median & $\begin{array}{l}\text { Minimum } \\
\text { Maximum }\end{array}$ & \\
\hline Age & $\begin{array}{l}8.20 \\
(1.7)\end{array}$ & 8.50 & $\begin{array}{c}6.00 \\
11.00\end{array}$ & $\begin{array}{l}8.11 \\
(1.8)\end{array}$ & 8.00 & $\begin{array}{c}6.00 \\
11.00\end{array}$ & $\begin{array}{l}8.20 \\
(1.7)\end{array}$ & 8.50 & $\begin{array}{c}6.00 \\
11.00\end{array}$ & ns \\
\hline Weigth & $\begin{array}{l}27.60 \\
(2.6)\end{array}$ & 28.00 & $\begin{array}{l}23.00 \\
31.00\end{array}$ & $\begin{array}{l}40.67 \\
(13.7)\end{array}$ & 39.00 & $\begin{array}{l}26.00 \\
69.00\end{array}$ & $\begin{array}{l}34.31 \\
(12.7)\end{array}$ & 32.85 & $\begin{array}{l}20.80 \\
66.70\end{array}$ & $* \mathrm{P}<0.05$ \\
\hline Height & $\begin{array}{l}132.7 \\
(7.0)\end{array}$ & 132.75 & $\begin{array}{l}122.50 \\
141.00\end{array}$ & $\begin{array}{l}138.22 \\
(10.7)\end{array}$ & 139.50 & $\begin{array}{l}124.00 \\
154.00\end{array}$ & $\begin{array}{l}126.40 \\
(10.3)\end{array}$ & 125.50 & $\begin{array}{l}113.00 \\
147.00\end{array}$ & ns \\
\hline BMI & $\begin{array}{c}15.68 \\
(1.0)\end{array}$ & 15.85 & $\begin{array}{l}14.00 \\
17.00\end{array}$ & $\begin{array}{c}20.72 \\
(3.8)\end{array}$ & 20.10 & $\begin{array}{l}16.90 \\
29.10\end{array}$ & $\begin{array}{c}20.86 \\
(4.4)\end{array}$ & 20.00 & $\begin{array}{l}15.40 \\
30.90\end{array}$ & $\ddagger \mathrm{P}<0.05$ \\
\hline
\end{tabular}

$* \mathrm{EG} \neq \mathrm{OG}$ and $\mathrm{DG}=\mathrm{EG} ; \neq \mathrm{EG} \neq \mathrm{DG} ; \mathrm{EG} \neq \mathrm{OG}$ and $\mathrm{DG}=\mathrm{OG} ; \mathrm{ns}=$ non-significant.

Table 2. Individual clinical and functional data of participants with Duchenne muscular dystrophy including age, Motor Function Measure (MFM), body mass index (BMI), and use of drugs and orthotic devices.

\begin{tabular}{|c|c|c|c|c|c|c|c|c|}
\hline \multicolumn{9}{|c|}{ Individual Clinical Features of DG Participants } \\
\hline Subject & $\begin{array}{c}\text { Age } \\
\text { (years) }\end{array}$ & $\begin{array}{l}\text { MFM D1 } \\
\quad(\%)\end{array}$ & $\begin{array}{l}\text { MFM D2 } \\
(\%)\end{array}$ & $\begin{array}{l}\text { MFM D3 } \\
(\%)\end{array}$ & $\begin{array}{c}\text { MFM } \\
\text { Total }(\%)\end{array}$ & BMI & Drugs & $\begin{array}{l}\text { Orthotic } \\
\text { devices }\end{array}$ \\
\hline A1 & 6 & 26 & 94 & 90 & 66 & 24.7 & $\begin{array}{c}\text { Periciazine, Prednisone, D } \\
\text { vitamin }\end{array}$ & Night Splint \\
\hline $\mathrm{A} 2$ & 6 & 46 & 89 & 90 & 72 & 17.5 & none & Night Splint \\
\hline A3 & 6 & 41 & 94 & 95 & 73 & 17.6 & Prednisone & $\begin{array}{c}\text { Night Splint and } \\
\text { Hinged AFO }\end{array}$ \\
\hline B1 & 8 & 49 & 97 & 100 & 78 & 19 & Deflazacort, D vitamin & $\begin{array}{l}\text { Night Splint and } \\
\text { Hinged AFO }\end{array}$ \\
\hline B2 & 8 & 59 & 100 & 100 & 83 & 15.4 & $\begin{array}{l}\text { Prednisone, D vitamin, } \\
\text { Levothyroxine sodium }\end{array}$ & none \\
\hline $\mathrm{C} 1$ & 9 & 56 & 100 & 100 & 82 & 19.1 & $\begin{array}{c}\text { Deflazacort, D vitamin, } \\
\text { Calcium }\end{array}$ & Night Splint \\
\hline $\mathrm{C} 2$ & 9 & 51 & 94 & 100 & 78 & 22 & $\begin{array}{l}\text { Prednisone, D vitamin, } \\
\text { Risperidone, Maprotiline }\end{array}$ & Night Splint \\
\hline $\mathrm{C} 3$ & 9 & 36 & 100 & 90 & 72 & 21.5 & Deflazacort, D vitamin & Hinged AFO \\
\hline D1 & 10 & 33 & 97 & 95 & 71 & 30.9 & Prednisone, D vitamin & $\begin{array}{c}\text { Night Splint and } \\
\text { Hinged AFO }\end{array}$ \\
\hline E1 & 11 & 38 & 94 & 100 & 73 & 20.9 & Prednisone, Imipramine & $\begin{array}{l}\text { Hinged AFO and } \\
\text { Leaf-spring }\end{array}$ \\
\hline
\end{tabular}

\section{Postural alignment}

There were differences between the DG and EG in horizontal alignment of the pelvis $(\mathrm{P}<0.05)$ while the DG and OG were similar in this variable. Analysis showed greater anteversion in the DG and OG compared to the EG $(\mathrm{P}<0.05)$.

Regarding sagittal plane asymmetry, which is a measure of anterior-posterior displacement, there were differences between the EG and the other groups $(\mathrm{p}<0.05)$. Although all participants presented anterior displacement of the CoM, the DG showed greater anterior displacement than the EG $(\mathrm{P}<0.05)$ and the
DG and OG were similar. No significant differences between groups were observed for the other variables of postural alignment as shown in Table 3 .

\section{Balance}

Balance scores (PBS) differed significantly between the $\mathrm{DG}, \mathrm{EG}$, and $\mathrm{OG}(\mathrm{P}<0.05)$, with median values of 42.5, 55.5, and 55, respectively (Figure 1). These data showed that the worst performance and the higher variability were recorded for the DG participants. 


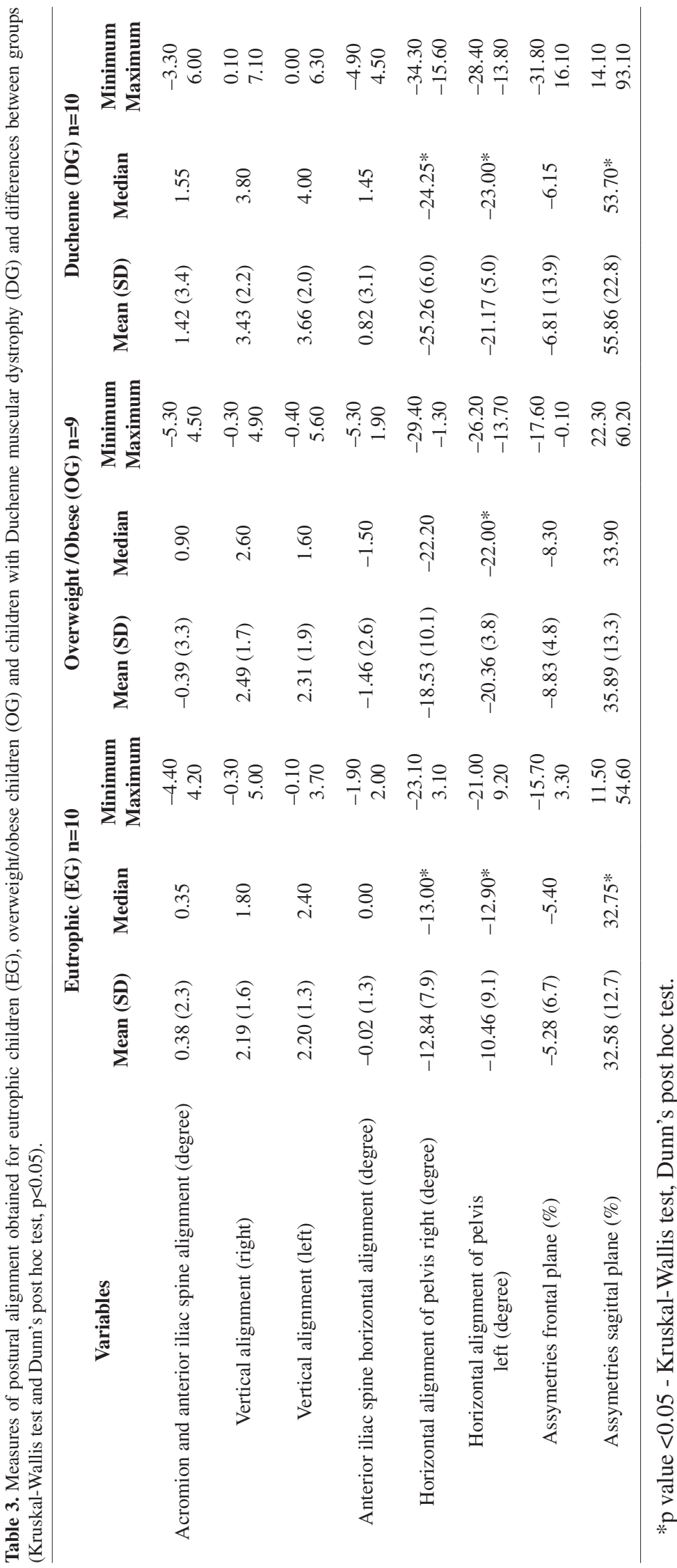




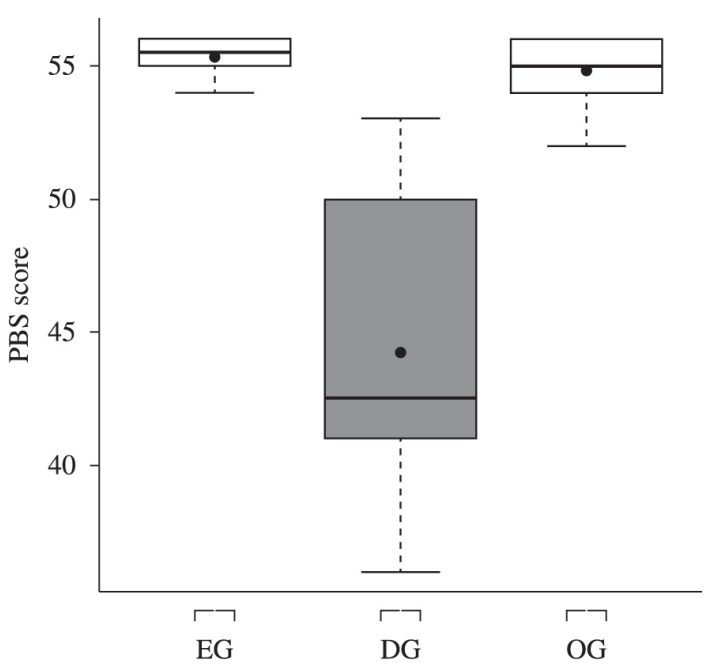

Figure 1. Box-plot of balance scores obtained for the eutrophic group (EG), Duchenne group (DG), and overweight/obese group (OG) with the Pediatric Balance Scale (PBS).

\section{Correlation between PBS scores and measures of postural alignment}

Considering the classification for the Spearman analysis, there was a moderate correlation between the PBS score and horizontal alignment of the pelvis on the right side (rho $=0.58$ ). Weak correlations were observed between the PBS score and horizontal alignment of the pelvis on the left side (rho $=0.47$ ) and asymmetry in the sagittal plane $($ rho $=-0.39)$.

\section{- Discussion}

Postural alignment measurement allowed us to identify one of the most important biomechanical factors affecting semi-static balance in DMD: pelvic inclination. Our data showed that, in general, the posture of children with DMD is similar to eutrophic or overweight/obese children, with the exception of pelvic alignment and asymmetries in the sagittal plane. Regarding pelvic alignment, the anteversion in the DG (-24.2 degrees) was similar to the OG ( -22.2 degrees) and twice that of the EG (-13.0 degrees). The most significant forward projection of the CoM was recorded in the children with DMD.

In this study, balance was assessed with the PBS, a non-trivial scale for neuromuscular disease. Although stabilometric tests provide objective measurements, a scale such as the PBS has the advantage of examining several functional aspects of balance. In this respect, the PBS was capable of discriminating children with DMD from non-affected children, showing potential as an assessment instrument. Eutrophic and obese children achieved similar scores, which allowed us to determine whether weight had any effect on the variables in the children with DMD. These data corroborate D'Hondt et al. ${ }^{13}$, who studied pediatric postural stability in four sensory conditions, using a force plate to quantify center of pressure (COP) dynamics. In this study, normal and overweight children were not different, however there is no consensus on balance deficits and weight gain. McGraw et al. ${ }^{11}$ and Goulding et al. ${ }^{12}$ pointed to low balance performance for overweight and obese boys without neuromuscular diseases. In relation to pediatric neuromuscular diseases, no reports were found in the literature. Based on our data, if the balance performance of DMD children was lower than that of the obese children and these were similar to the healthy children, then obesity did not have a considerable impact on the balance performance of the DMD children.

The investigation of the relationship between functional balance and postural alignment confirmed the influence of pelvic alignment. The moderate correlation between balance and horizontal alignment of the pelvis means that pelvic anteversion accompanies higher balance scores. This finding must be analyzed with caution because children with excessive anteversion could be more affected and demand more compensation.

The postural deviations observed in this series of children with DMD may be due to the muscle weakness and shortening or even to the joint deformities that are typical of this population ${ }^{22}$. In healthy children, posture development in the sagittal plane is characterized by relative anterior translation of the head, shoulders, hips, and knees ${ }^{23}$, and lumbar lordosis increases between the ages of 3 and 12 then decreases from the ages of 13 to $15^{24}$. There are no studies providing quantitative data on postural misalignment in children with neuromuscular diseases, particularly those with DMD. In this respect, the present data for alignment of sagittal plane posture, but not of frontal plane posture, allowed us to distinguish healthy children from children with DMD. Alignment of the pelvis differed significantly between the groups with and without DMD $(\mathrm{P}<0.05)$, showing greater pelvis tilt amplitudes and anterior projection of the CoM in the DG.

The anterior projection of the CoM observed in children with DMD may be due to the interaction of multiple factors, such as muscle shortening and muscle strength imbalance (agonist/antagonist ratio). According to Caromano ${ }^{25}$, the shortening of plantar flexor muscles, frequently seen in children with DMD, induces clubfoot and excessive lateral displacements of the trunk during walking. From a functional point of view, anterior projection of the CoM over the base of support increases the susceptibility for falls. Lajoie and Gallagher ${ }^{26}$ showed in older adults that the greater 
lateral and anterior excursions, the lower control of balance. Here, therefore, is the correlation between some variables of alignment and PBS scores.

In the present series, indirect measures of CoM demonstrated anterior and lateral displacement in all participants, with greater sagittal plane asymmetry in the DG compared to the EG $(\mathrm{p}<0.05)$. Frontal and sagittal plane asymmetries allow us to infer the direction of $\mathrm{CoM}$ displacement. Frontal plane analysis provides data regarding medial-lateral displacement, whereas analysis in the sagittal plane indicates anterior-posterior displacement. These present findings agree with Barrett et al. ${ }^{8}$ who also observed anterior projection of the center of gravity in 61 children with DMD evaluated on a force plate. Furthermore, Dalleau et al. ${ }^{27}$, studying 21 adolescent girls with scoliosis on a force plate, attributed anterior projection of the center of gravity to pelvic anteversion, which promotes an increase in lumbar lordosis and posterior displacement of the trunk. Despite the differences in methodology and pathological condition, this suggestion seems to be in line with the present study, since pelvic anteversion and anteriorization of the center of gravity were common findings in all children with DMD.

The PBS scores used for balance assessment can vary from 0 to 56 , corresponding to increasing performance. According to Newstead et al..$^{28}$ who evaluated adults with brain damage, each point deducted on the Berg Balance Scale indicates an increasing risk of falls: a decline from 56 to 54 increases the risk of falls by 3 to $4 \%$, from 54 to 46 by 6 to $8 \%$, and the risk of falls is almost $100 \%$ when the subject scores less than 36 . No such data are available for the pediatric population. Therefore, comparisons need to be done between children with and without DMD. A study on this topic was conducted by Franjoine et al. ${ }^{29}$ and showed the scores achieved by normal children aged 2.6 to 13.7 years. The authors demonstrated that the score increased with advancing age from the second to the seventh year, with girls reaching the highest scores.

For our study, a significant difference in the performance of the balance tasks was observed between groups, with a median score of 55.5 for the EG, 55 for the OG, and 42.5 for the DG, demonstrating low performance and high risk of falls in DMD. The clinical relevance of this finding was in agreement with another functional scale specific for neuromuscular diseases, the MFM. The score obtained in the MFM indicates the level of functional impairment in patients with DMD. According to Vuillerot et al. ${ }^{30}$, a total score of $58 \%$ separates ambulant from non-ambulant patients, irrespective of age. Thus, the children of the DG presented good motor function (scores higher than 66 points) but impairment in balance detectable with the PBS.

The relevance of the present study lies in the fact that it provides quantitative data of proximal postural deviations in children with DMD and correlates them with functional measures of balance.

In conclusion, the distinction between the DMD children and the non-affected children is based on horizontal pelvic alignment and sagittal-plane asymmetry. Boys with DMD presented excessive forward projection of the CoM, exacerbated pelvic anteversion, and the worst balance scores. The excessive pelvic anteversion of the DMD seems to aid balance, however this strategy did not guarantee a similar performance as that achieved by the eutrophic or obese children. Further investigations into proximal alignment should focus on the impact of muscle shortening, i.e. plantar flexion.

\section{Acknowledgements}

The CEMEC for their statistical advice and doctor Claudia Ferreira Rosa Sobreira for analysing medical records and diagnostic classification of the DMD patients.

\section{References}

1. Kinali M, Main M, Mercuri E, Muntoni F. Evolution of abnormal postures in Duchenne muscular dystrophy. Ann Indian Acad Neurol. 2007;10:44-54.

2. Souza HP. A postura do estudante. Vida e Saúde. 1995;6-7.

3. Santos NM, Rezende MM, Terni A, Hayashi MCB, Fávero FM, Quadros AAJ, et al. Perfil clínico e funcional dos pacientes com distrofia muscular de Duchenne assistidos na Associação Brasileira de Distrofia Muscular (ABDIM). Rev Neurociênc. 2006;14:15-22.

4. McDonald CM, Abresch RT, Carter GT, Fowler WM, Johnson ER, Kilmer D, et al. Profiles of neuromuscular diseases. Duchenne muscular dystrophy. Am J Phys Med Rehabil. 1995;74:70-92. http://dx.doi. org/10.1097/00002060-199509001-00003

5. Okama LO, Queiroz PD, Spina LR, Miranda MBL, Curtarelli MB, Faria M Jr, et al. Avaliação funcional e postural nas distrofias musculares de Duchenne e Becker. ConScientiae Saúde. 2010;9:649-58.

6. Aras B, Aras O, Karaduman A. Reliability of balance tests in children with Duchenne muscular dystrophy. Sci Res Essays. 2011;6:4428-31.

7. Barrett R, Hyde SA, Hark WB. The design of a force platform for clinical use: a feasibility study of stabilography in evaluating the effect of orthotic intervention in Duchenne muscular dystrophy. Med Eng Technol. 1987;11:68-73. http://dx.doi.org/10.3109/03091908709062798

8. Barrett R, Hyde SA, Scott OM, Dubowitz V. Changes in center of gravity in boys with Duchenne muscular dystrophy. 
Muscle Nerve.1988;11:1157-63. PMid:3226433. http:// dx.doi.org/10.1002/mus.880111109

9. Kelly CR, Redford JB, Zilber S, Madden PA. Standing balance in healthy boys and in children with Duchenne muscular dystrophy. Arch Phys Med Rehabil. 1981;62:3247. PMid:7247659.

10. Reed UC. Doenças neuromusculares. J Pediatr. 2002;78:89-103. http://dx.doi.org/10.1590/ S0021-75572002000700012

11. McGraw B, McClenaghan BA, Williams HG, Dickerson J, Ward DS. Gait and postural stability in obese and nonobese prepubertal boys. Arch Phys Med Rehabil. 2000;81:484-9. PMid:10768540. http://dx.doi.org/10.1053/mr.2000.3782

12. Goulding A, Jone IE, Taylor RW, Piggot JM, Taylor D. Dynamic and static tests of balance and postural sway in boys: effects of previous wrist bone fractures and high adiposity. Gait Posture. 2003;17:136-41. http://dx.doi. org/10.1016/S0966-6362(02)00161-3

13. D'Hondt E, Deforche B, De Bourdeaudhuij I, Gentier I, Tanghe A, Shultz S, et al. Postural balance under normal and altered sensory conditions in normalweight and overweight children. Clin Biomech (Bristol, Avon). 2011;26(1):84-9. PMid:20850213. http://dx.doi. org/10.1016/j.clinbiomech.2010.08.007

14. Iwabe C, Miranda-Pfeilsticker BH, Nucci A. Motor function measure scale: portuguese version and reliability analysis. Rev Bras Fisioter. 2008;12(5):417-24. http:// dx.doi.org/10.1590/S1413-35552008000500012

15. Ries LGK, Michaelsen SM, Soares PSA, Monteiro VC, Alegretti KMG. Cross-cultural adaptation and reliability analysis of the Brazilian version of Pediatric Balance Scale (PBS). Rev Bras Fisioter. 2012;16(3):20515. PMid:22699691. http://dx.doi.org/10.1590/ S1413-35552012005000026

16. Franjoine MR, Gunther JS, Taylor MJ. Pediatric balance scale: a modified version of the Berg Balance Scale for the school-age child with mild to moderate motor impairment. Pediatr Phys Ther. 2003;15:114-28. PMid:17057441. http://dx.doi.org/10.1097/01.PEP.0000068117.48023.18

17. Iunes DH, Castro, FA, Salgado HS, Moura IC, Oliveira AS, Bevilaqua-Grossi D. Confiabilidade intra e interexaminadores e repetibilidade da avaliação postural pela fotogrametria. Rev Bras Fisioter. 2005;9:327-34.

18. Santos MM, Silva MPC, Sanada LS, Alves CRJ. Photogrammetric postural analysis on healthy seven to ten-year-old children: interrater reliability. Rev Bras Fisioter. 2009;13(4):350-5. http://dx.doi.org/10.1590/ S1413-35552009005000047

19. Projeto Software para Avaliação Postural. Incubadora Virtual Fapesp. 2004 [cited 2012 Aug 20]. Available from: http://sapo.incubadora.fapesp.br/portal.

20. Development Core Team R: A language and environment for statistical computing. Vienna: R Foundation for Statistical Computing; 2011 [cited 2013 May 10]. Available from: http://www.R-project.org/.

21. World Health Organization - WHO. Multicentre Growth Reference Study Group. WHO Child Growth Standards: length/height-for-age, weight-for-age, weight for-length, weight-for- height and body mass index-for-age: methods and development. Geneva: WHO; 2006.

22. Hsu JD, Furumasu J. Gait and posture changes in the Duchenne muscular dystrophy child. Clin Orthop Relat Res. 1993;288:122-5. PMid:8458124.

23. Lafond D, Descarreaux M, Normand MC, Harrison DE. Postural development in school children: a cross - sectional study. Chiropr Osteopat. 2007;15:1-7. PMid:17204148 PMCid:PMC1781952. http://dx.doi. org/10.1186/1746-1340-15-1

24. Cil A, Yazici M, Uzumcugil A, Kandemir U, Alanay A, Alanay Y, et al. The evolution of sagittal segmental alignment of the spine during childhood. Spine. 2005;30:93-100. PMid:15626988.

25. Caromano FA. Características do portador de distrofia muscular de Duchenne (DMD). Arq Ciênc Saúde Unipar. 1999;3:211-8.

26. Lajoie Y, Gallagher SP. Predicting falls within the elderly community: comparison of postural sway, reaction time, the Berg Balance Scale and the Activities-Specific Balance Confidence $(\mathrm{ABC})$ scale for comparing fallers and nonfallers. Arch Gerontol Geriatr. 2004;38:11-26. http:// dx.doi.org/10.1016/S0167-4943(03)00082-7

27. Dalleau G, Damavandi M, Leroyer P, Verkindt C, Rivard $\mathrm{CH}$, Allard P. Horizontal body and trunk center of mass offset and standing balance in scoliotic girls. Eur Spine J. 2010;20:123-8. PMid:20700609 PMCid:PMC3036026. http://dx.doi.org/10.1007/s00586-010-1554-Z

28. Newstead AH, Hinman MR, Tomberlin JA. Reliability of the Berg Balance Scale and balance master limits of stability tests for individuals with brain injury. J Neurol Phys Ther. 2005;29:18-23. PMid:16386157. http://dx.doi. org/10.1097/01.NPT.0000282258.74325.cf

29. Franjoine MR, Darr N, Held SL, Kott K, Young BL. The performance of children developing typically on the pediatric balance scale. Pediatr Phys Ther. 2010;22(4):350-9. PMid:21068635. http://dx.doi. org/10.1097/PEP.0b013e3181f9d5eb

30. Vuillerot C, Girardot F, Payan C, Fermanian J, Iwaz J, De Lattre $\mathrm{C}$, et al. Monitoring changes and predicting loss of ambulation in Duchenne muscular dystrophy with the Motor Function Measure. Dev Med Child Neurol. 2010;52:60-5. PMid:19453691. http://dx.doi. org/10.1111/j.1469-8749.2009.03316.x

\section{Correspondence}

\section{Cyntia Rogean de Jesus Alves de Baptista}

Universidade de São Paulo

Faculdade de Medicina de Ribeirão Preto

Departamento de Biomecânica, Medicina e Reabilitação do

Aparelho Locomotor

Curso de Fisioterapia

Av. Bandeirantes, 3900

CEP 14049-900, Ribeirão Preto, SP, Brazil

e-mail: crogean@fmrp.usp.br 